\title{
Conceptualizing Community Oriented Primary Care (COPC) - the Tshwane, South Africa, health post model
}

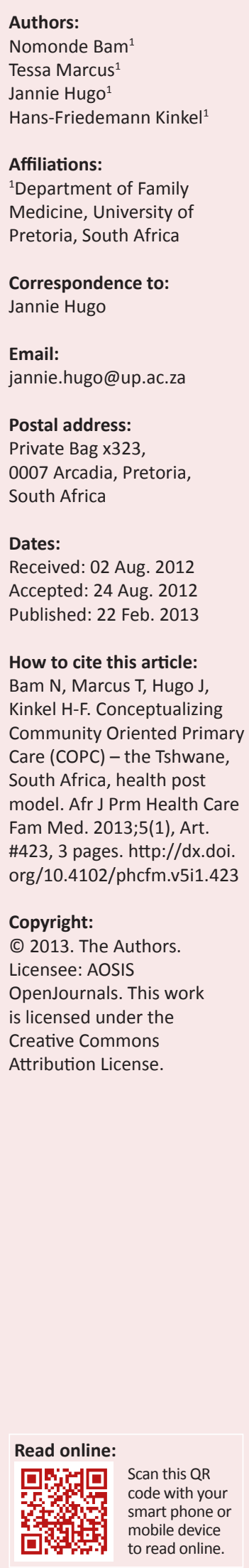

\section{Introduction}

\section{Re-engineering primary health care}

Health sector reforms initiated in South Africa in 1994 adopted a primary health care approach to strengthen the health system and achieve public health outcomes through disease prevention and health promotion. ${ }^{1}$ This led to the building of many new clinics to make health services more accessible, affordable and equitable. However, the pressures of a predominantly hospitalcentric health care system and emerging epidemics prevented the successful provision of quality comprehensive, integrated primary care to millions of South Africans. Also, little attention was given to community partnerships and multi-sectoral collaboration.

This had two related negative consequences for health care services. Primary health care became a passive, low quality and episodic service of individuals in clinics, whilst hospitals were overburdened with referrals and patients seeking help. Compounded by a burgeoning burden of disease, pressure on the system increased exponentially and it was therefore not able to improve health outcomes. ${ }^{2}$

Dr Aaron Motsoaledi, the minister of health, intended to address these challenges in the 2010 'Revitalisation of Primary Health Care' initiative by re-engineering primary health care towards proactive household- and community-focused interventions. ${ }^{3}$ Acknowledging health care as a universal right, the approach encompasses promotion of healthy living, disease prevention, early detection, treatment of illness, community-based disease management and rehabilitation. Practically, the initiative comprise of municipal ward outreach teams, district specialists teams and school health teams. ${ }^{3,4}$

Following the National Minister of Health's initiative, the then member of the executive committee (MEC) for health in Gauteng, Ms Qedani Mahlangu, announced the adoption of Community Oriented Primary Care (COPC) as Gauteng's approach to re-engineering primary health care. This was articulated in the 2010-2020 Service Transformation Plan and saw the creation of health posts. ${ }^{5}$ It then cascaded to the district level, where the University of Pretoria's Faculty of Health Sciences, through its Community Engagement office, facilitated a process with the Tshwane District Office of the Gauteng Department of Health and Social Development. In 2010, the departments of Family Medicine at the Universities of Pretoria and Limpopo, together with the Tshwane District Office of the Gauteng Department of Health and Social Development, developed a conceptual framework for implementing COPC through health posts in Tshwane. The approach was supported by USAID funding through the Foundation for Professional Development (FPD).

This article briefly describes the health post model of COPC in Tshwane as an approach to primary health care re-engineering. How the model unfolds in the future will be described and analysed in subsequent publications based on a built-in process of participatory action research (The National Department of Health is using the term 'Ward Based Outreach Team' [WBOT] in place of 'Health Post' and that is the term that is used in the field and in future publications).

\section{Community Oriented Primary Care (COPC)}

With the implementation of COPC, the Tshwane District Office of the Gauteng Department of Health joins a globally established approach to primary health care that originated in South Africa about seven decades ago with Sidney and Emily Kark. ${ }^{6,7,9,10}$ (The history of COPC in South Africa is summarised elsewhere $\left.{ }^{8,11,12}\right)$.

Briefly, COPC is grounded in the notion that people's health is determined by their social environment. ${ }^{13,14}$ This means that individual and population level improvements in health cannot be achieved without simultaneously changing the social determinants that shape health more generally. COPC has been summarily described as 'the merger of front line clinical medicine with public health'. ${ }^{11,14}$ As such, COPC addresses individual health needs in the collective context 
of family and community. COPC is characterised by local specificity that derives from the behavioural, cultural and social characteristics of people who live in particular places. ${ }^{14}$ Also, COPC is rendered by multi-disciplinary teams that work collaboratively with local people. COPC uses epidemiology as a tool for practicing health care and evaluating its effects on a systematic and continuous basis..$^{15,16,17}$ It also integrates research, teaching and learning into the practice of health care delivery. ${ }^{18,19,20}$

COPC contributes to broader human development both by advancing health literacy and social capabilities, as well as by engaging with the socio-economic and politico-cultural determinants of health and disease. ${ }^{21}$ As such, health care is achieved through empowerment as much as through improved service delivery. ${ }^{22,23,24}$

\section{The Tshwane Health Post Model}

\section{COPC in Tshwane District,}

[...] is designed around health posts. These are both structures that are physically located in communities and they are health care practitioner teams, initially comprising professional nurses and CHWs [community health workers]. As teams, their responsibility is to interact in a proactive way with every household (as a collective, as well as with individual members) in their jurisdiction. Their role is to promote health, prevent disease and detect disease early, and support treatment, rehabilitation and palliation, and to do this in a way that both develops capacity and shared responsibility for heath care between service providers and service users. ${ }^{25}$

\section{What the health post is}

The health post is developed as a service unit that is physically located in a community and serves the population in a defined geographic area within a specific municipal ward. ${ }^{5,26}$ It has been conceptualised as a 'nerve centre' that drives and coordinates all primary care interventions in the community..$^{5,21}$

Each health post serves between 2000 and 3000 households in a defined geographic area within a municipal ward. ${ }^{5}$ Whilst the intention is to expand health posts to the 44 wards of Tshwane District, the first nine health posts were initiated in the poorest wards in priority areas in each subdistrict of the region. On initiation, the geophysical area served by the health post is identified and mapped using ward-based maps to define the boundaries of health post activity. Each community health worker (CHW) is assigned between 150 and 200 households, although the ideal ratio of households per CHW has yet to be tested in practice for feasibility and impact.

At its core, the health post team comprises a health post manager and between 20 and $40 \mathrm{CHWs}$ - proportionate to the number of households served. The health post manager is a professional nurse and the CHWs are recruited from the communities surrounding the health posts. This approach enables the team to work from a sound understanding of the local culture and idiom, although there is the risk of overfamiliarity and problems associated with privacy. ${ }^{25}$
For the most part, the health post is hosted by existing community-based nonprofit organisations (NPOs). This approach to COPC was deliberately adopted because these organisations have historically established structures and links in the communities. Their familiarity with local people and practices provides a base for COPC and shortens the time it takes to develop acceptability and mutual trust. In addition, their knowledge of the communities makes a significant contribution to planning and intervention. Lastly, they have administrative structures in place that facilitate employment relations and daily team functioning. The linking of the health posts to existing NPOs also inevitably poses some challenges to all parties, since they each bring their own practice legacies around focus of service, funding and authority structures..$^{25}$

\section{What the health post does}

As an entry point into the health and social care systems, health post teams engage with individuals and families in a continuous, comprehensive and integrative way that is information-led. Continuity means building interpersonal relations between individuals and families, and members of the health post team over time. Continuity also means continuity of care over the course of a condition or life period. Comprehensiveness means ensuring that the multiplicity of health needs, from promotion to palliation, are responded to in a reflective way. Integration means engaging with healthrelated socio-economic, cultural and environmental issues directly with individuals and families and building working relations with relevant partner organisations and institutions in the respective areas. Within the health care system, integration means collaborating actively with school health and district specialist teams in the envisaged National Health Insurance (NHI) model.

COPC begins by familiarising the health post team with the organisations that are active in their sites and the individuals and families who live in the households they will serve. Practically, the former involves conducting an institutional assessment to see how existing organisations work and the contribution they could make to the health post. The latter involves carrying out household registration and individual structured health status assessments in order to establish individual, household and community baselines. These are used to understand the predominant health issues and to determine priority interventions at all levels. This assessment is ongoing so that new issues can be identified and responded to as they arise in a continuous and iterative way.

The health status assessment data is captured electronically by the health post team using mobile phones. The data is transmitted to a web-based data platform. It is then kept at the health post as a family file. Using daily electronic reports on all CHW visits and interventions, as well as additional verbal reports from $\mathrm{CHWs}$, the health post manager is able to allocate daily tasks and address health and social challenges for each household as they arise. ${ }^{27}$ The family files are also confirmed, refined and updated through regular home visits. In addition, data is aggregated for community level 
assessments and broad strategic health campaigns. The health post team, together with district managers, the University of Pretoria and other collaborating partners, use this data to determine short, medium and longer term interventions. By the end of July 2012, over 40000 individual health status assessments had been carried out at the health posts and prioritization for strategic intervention was in progress.

\section{Conclusion}

With its health post model, Tshwane District has embarked on an innovative journey to address the health needs of ordinary South Africans through COPC. It focuses on continuous, comprehensive, integrated and informed health care. As an active collaboration between health services, universities and funding agencies and communities, the Tshwane model creates a platform on which to successfully re-engineer primary health care in South Africa.

\section{Acknowledgements}

The authors thank dr Manei Letebele and mrs Lekwetji Mamabolo (Tshwane District, Gauteng Department of Health and Social Development) for their contribution to the project, the Foundation for Professional Development for the financial support, as well as the peer reviewers for their constructive inputs.

\section{Competing interests}

The authors declare that they have no financial or personal relationship(s) that may have inappropriately influenced them in writing this article.

\section{Authors' contribution}

All authors were involved in conceptualising and establishing COPC in Tshwane District, South Africa. N.B. (University of Pretoria) conceptualised the article and prepared the manuscript draft. T.M. (University of Pretoria) made important conceptual contributions to the paper and assisted in the preparation of the manuscript. J.H. (University of Pretoria) made important conceptual contributions to the manuscript. H-F.K. (University of Pretoria) contributed to the concept of the article and the preparation of the manuscript.

\section{References}

1. National Department of Health (NDOH), Republic of South Africa. White Paper for the transformation of the health system in South Africa [homepage on the Internet]. 1997 [updated 2008 Apr 23; cited 2012 Aug 14]. Available from: http:// www.info.gov.za/whitepapers/1997/health.htm

2. Chopra M, Lawn JE, Sanders $D$, et al. Achieving the health Millennium Development Goals for South Africa: challenges and priorities. Lancet, 2009 19;374(9694):1023-1031.
3. National Department of Health (NDOH), Republic of South Africa. National Department of Health Strategic Plan 2010/2011 - 2012/2013. Report. Pretoria: Department of Health [homepage on the Internet]. 2010. p. 116. [cited 2012 July 31]. Available from: http://hs.ukzn.ac.za/Libraries/Postgraduate_Administrative

4. Subedar H. Provincial guidelines for the implementation of the three streams of the PHC re-engineering. Guideline. Pretoria: Department of Health [homepage on the Internet]. 2011 Sep. p. 10. [cited 2012 July 31]. Available from: http://www. $\mathrm{cmt}$.org.za/wp-content/uploads/2011/09/guidelines-for-the-implementation-of-
the-three-streams-of-phc-4-Sept-2.pdf

5. Gauteng Department of Health and Social Development. Service Transformation Plan 2010-2020. Pretoria: Gauteng Department of Health and Social Development; 2010 Oct. p. 237.

6. Kark S. A health unit as family doctor and health advisor. SAMJ. 1944;18(2):39-46.

7. Kark S, Cassel J. The Pholela Health Centre. A Progress Report. SAMJ. 1952;26(6): 101-104 \& 131-136.

8. Longlett SK, Kruse JE, Wesley RM. Community-oriented primary care: historical perspective. J Am Board Fam Pract. 2001;14(1):54-63. PMid:11206694

9. Moosa SAH. Community-oriented primary care (COPC) in district health services of Gauteng, South Africa. SA Fam Pract. 2006;48(4):6-8.

10. Mullan F, Epstein L. Community-oriented primary care: new relevance in a changing world. Am J Public Health 2002;92(11):1748-1755. http://dx.doi.org/ 10.2105/AJPH.92.11.1748, PMid:12406800, PMCid:3221479

11. Geiger HJ. Community-oriented primary care: the legacy of Sidney Kark. Am J Public Health 1993;83(7):946-947. http://dx.doi.org/10.2105/AJPH.83.7.946, PMid:8328614, PMCid:1694772

12. Susser M. A South African odyssey in community health: a memoir of the impact of the teachings of Sidney Kark. Am J Public Health. 1993;83(7):1039-1042. http://dx.doi.org/10.2105/AJPH.83.7.1039, PMid:8328603, PMCid:1694783

13. Starfield B. Politics, primary health care and health: was Virchow right? Epidemiol Community Health. 2011;65(8):653-655. http://dx.doi.org/10.1136/ jech.2009.102780, PMid:21727176

14. Gofin J. On 'A practice in social medicine' by Sidney and Emily Kark. Social Medicine. 2006;1(2):107-115

15. Abramson JH. Application of epidemiology in community oriented primary care. Public Health Rep. 1984;99(5):437-442. PMid:6435152

16. Mettee TM, Martin KB, Williams RL. Tools for community-oriented primary care: a process for linking practice and community data. J Am Board Fam Pract. 1998;11(1):28-33. PMid:9456444

17. Abramson JH, Kark SL. Community oriented primary care: meaning and scope. In: Connor E, Mullan F, editors. Community oriented primary care. New directions for health services delivery. Conference proceedings. Washington D.C., United States: National Academic Press; 1983.

18. Bonafede K, Reed VA, Pipas CF. Self-directed community health assessment projects in a required family medicine clerkship: an effective way to teach communityoriented primary care. Fam Med. 2009;41(10):701-707. PMid:19882393

19. Cashman SB. Teaching community-oriented primary care. Fam Med. 1998;30(10): 696-697. PMid:9827338

20. Art B, De Roo L, De Maeseneer J. Towards unity for health utilising communityoriented primary care in education and practice. Educ Health (Abingdon). 2007;20(2):74.

21. Marcus T. Community Oriented Primary Care L2 Principles: the individual the family and the social structure of society. Johannesburg, South Africa: Pearson Cheer; Forthcoming in 2013.

22. Geiger HJ. Community-oriented primary care: a path to community development. Am J Public Health. 2002;92(11):1713-1716. http://dx.doi.org/10.2105/AJPH.92. 11.1713, PMid:12406790, PMCid:3221474

23. Mack M, Uken R, Powers J. People improving the community's health: community health workers as agents of change. J Health Care Poor Underserved. 2006;17(Suppl 1):16-25. PMid:16520502

24. Heritage $Z$, Dooris $M$. Community participation and empowerment in healthy cities. Health Promot Int. 2009;24(suppl.1):(i45-i55). http://dx.doi.org/10.1093/ heapro/dap054, PMid:19914988.

25. Kinkel HF, Marcus T, Memon S, Bam N, Hugo J. COPC in Tshwane District, South Africa: Assessing the first phase of implementation. African Afr J Prm Health Care Fam Med. 2012;4(1), (in review)

26. Kautzky K, Tollman SM. A perspective on primary health care in South Africa. In: Barron P, Roma-Reardon J, editors. South African health review. Durban: Health Systems Trust; 2008. p. 17-31.

27. Kinkel HF, De Vos J, Hugo J. Using mobile GMS phones to capture health status assessments in COPC: Is the data plausible? Paper presented at: ICT4HALTH Conference; 2012 Sep. 12-13; Cape Town, South Africa. 